\title{
Measurements of the water balance components of a large green roof in the greater Paris area
}

\author{
Pierre-Antoine Versini ${ }^{1}$, Filip Stanic ${ }^{1,2}$, Auguste Gires ${ }^{1}$, Daniel Schertzer $^{1}$, and Ioulia Tchiguirinskaia ${ }^{1}$ \\ ${ }^{1}$ HM\&Co, École des Ponts ParisTech, Champs-sur-Marne, 77455, France \\ ${ }^{2}$ Navier, École des Ponts ParisTech, Champs-sur-Marne, 77455, France \\ Correspondence: Pierre-Antoine Versini (pierre-antoine.versini@enpc.fr)
}

Received: 3 October 2019 - Discussion started: 19 November 2019

Revised: 28 February 2020 - Accepted: 24 March 2020 - Published: 6 May 2020

\begin{abstract}
The Blue Green Wave of Champs-sur-Marne (France) represents the largest green roof ( 1 ha) of the greater Paris area. The Hydrology, Meteorology and Complexity lab of École des Ponts ParisTech has chosen to convert this architectural building into a full-scale monitoring site devoted to studying the performance of green infrastructures in storm-water management. For this purpose, the relevant components of the water balance during a rainfall event have been monitored: rainfall, water content in the substrate, and the discharge flowing out of the infrastructure. Data provided by adapted measurement sensors were collected during $78 \mathrm{~d}$ between February and May 2018. The related raw data and a Python program transforming them into hydrological quantities and providing some preliminary elements of analysis have been made available. These measurements are useful to better understand the hydrological processes (infiltration and retention) conducting green roof performance and their spatial variability due to substrate heterogeneity. The data set is available here: https://doi.org/10.5281/zenodo.3687775 (Versini et al., 2019b).
\end{abstract}

1

Considered to be part of Blue Green Solutions (BGS), green roofs are recognized as multifunctional assets able to provide several ecosystem services (Francis and Jensen, 2017; Oberndorfer et al., 2007) to face climate change and unsustainable urbanization consequences (such as biodiversity conservation or thermal insulation). They appear to be particularly relevant in storm-water management as they have the ability to store a more or less significant portion of precipitation (Stovin et al., 2012; Versini et al., 2016). Indeed, at the building scale, green roofs contribute to (i) reducing runoff volume at the annual scale and (ii) attenuating and delaying the peak at the rainfall event scale. This performance depends on the green roof properties (substrate depth, porosity, or vegetation type), rainfall intensity, and antecedent soil moisture conditions (Berndtsson, 2010). Considered to be storm-water source control facilities, they can act to manage rainwater at a small scale (about $10^{2}-10^{3} \mathrm{~m}^{2}$ ) to solve or prevent intermediate-scale $\left(10^{4}-10^{6} \mathrm{~m}^{2}\right)$ storm-water issues.
By increasing the storage of water, green roofs contribute to reducing the rainwater reaching the storm-water management network. It is particularly relevant to comply with regulation rules that are generally adopted by local authorities in charge of storm-water management, usually divided in two categories: flow-rate-based regulation and volume-based regulations (Petrucci et al., 2013). As green roofs perform both retention (ability to permanently hold back water by storing the water for subsequent removal by evapotranspiration) and detention (ability to temporarily hold back the water) (Johannessen et al., 2018), they can be used as relevant tools to ensure both kinds of regulation.

Indeed, for a green roof located in the greater Paris area (characterized by a temperate climate), the water balance during a rainfall event can be reduced to three components (see Eq. 1) as evapotranspiration can be neglected:

$P=Q+\Delta S$,

where $P$ is the precipitation, $Q$ the discharge flowing out of the structure, and $\Delta S$ the variation in water stored in the 
substrate conducting both retention and detention properties. All quantities are expressed in cubic metres.

Many experimental set-ups were implemented to monitor, assess, and understand the hydrological behaviour of green roofs (see Berndtsson, 2010, for a review). Most of them were conducted on small green roof modules or plots (Berretta et al., 2014; Getter et al., 2007; Li and Babcock, 2015; Locatelli et al., 2014; Loiola et al., 2019; Poë et al., 2015; Stovin et al., 2015; Wong and Jim, 2015; Zhang et al., 2015) characterized by an area ranging from 0.5 to $3 \mathrm{~m}^{2}$. These modular structures make possible the modification of green roof configuration and study of the effects of substrate (depth and nature), vegetation type, slope, or climate conditions on its performance. Some of them were also monitored in controlled conditions (Ouldboukhitine et al., 2011; Poë et al., 2015) to assess the respective impacts of temperature, irrigation, and light on green roof behaviour for instance.

In addition, few studies were conducted at full-scale green roofs. Indeed, such large structures were usually not planned for monitored during their construction and became hard to be monitored after. For instance, once built, electric connection is rarely compatible with the conservation of the roof sealing. To the knowledge of the authors, only the following works can be mentioned.

Palla et al. (2009a) studied an instrumented portion $\left(170 \mathrm{~m}^{2}\right)$ of a green roof in Genoa (Italy) under the Mediterranean climate. This pilot site was equipped to monitor the different components of the water balance with a meteorological station for rainfall, several time domain reflectometry probes installed horizontally along a vertical profile for retention in the substrate, and triangular weir and tipping-bucket devices to follow the outflowing discharge.

Hakimdavar et al. (2016) used the data collected on three full-scale extensive green roofs in New York City (USA) to validate a modelling approach based on the Soil Water Apportioning Method (SWAM). Under a humid continental climate, these monitored drainage areas ranged between 310 and $940 \mathrm{~m}^{2}$. The three main components of the water balance were measured: rainfall with a weather station, water content with soil moisture and water content reflectometer sensors, and discharge with a custom-designed weir placed in the drain of the green roof.

Fassman-Beck et al. (2013) assessed several green roofs in Auckland (New Zealand) under a subtropical climate. Their areas ranged between 17 and $171 \mathrm{~m}^{2}$. As the experimental set-up was focused on the rainfall-runoff relationship, only these components were measured: rainfall with a tippingbucket rain gauge and discharge (deduced from water level) from a water pressure transducer and a custom-designed orifice restricted device.

Cipolla et al. (2016) analysed runoff from a $60 \mathrm{~m}^{2}$ green roof in Bologna (Italy) characterized by a humid temperate subcontinental climate. Continuous weather data and runoff were especially monitored for modelling development. Runoff was estimated by using an in-pipe flowmeter consisting of a runoff chamber with an outlet weir and an ultrasonic sensor (to detect water level). The site was also equipped with a weather station measuring several meteorological variables (rainfall, wind speed, wind direction, relative humidity, atmospheric temperature, etc.).

Although these works were focused on the hydrological behaviour of green roofs, few of them have actually monitored the three components of the water balance. Rainfall and discharge were generally considered to be sufficient to assess its performance. Some additional studies can also be mentioned, but as they were focused on other topics (evapotranspiration processes, Feng et al., 2018; or water quality, Buffam et al., 2016), only one component on the water balance was assessed.

The full-scale monitoring experiments mentioned above also suffered from two limitations. First, they were still dedicated to rather small green roof areas. As the hydrological performance of a green roof is influenced by the size of the plot (water detention depends on water routing in the structure for instance), larger infrastructure should be studied. Second, very few measurements are performed (usually only one!) to assess water content on the whole vegetated surface. Indeed, green roof substrates - which are usually largely composed of mineral components - are very heterogeneous, causing variability in their infiltration and retention capacities. Therefore, large-scale monitoring set-ups able to capture this heterogeneity are required to better understand green roof hydrological behaviour and to study the spacetime variability of the involved processes.

Based on these considerations, this paper aims to present and make available the water balance data collected on a large green roof (called Blue Green Wave) located close to Paris (temperate climate) in order to study its hydrological behaviour and its ability to be used as a storm-water management tool. The monitoring set-up has been specifically tailored to take into account the space-time variability of the water balance components.

\section{Materials and method}

\subsection{The Blue Green Wave}

The Blue Green Wave (BGW) is a large (1 ha) wavy-form vegetated roof located in front of École des Ponts ParisTech (ENPC, Champs-sur-Marne, France). For now it represents the largest green roof of the greater Paris area. From its implementation in 2013, the BGW has been considered to be a demonstrative site oriented to Blue Green Solutions research (Versini et al., 2018). This experimental set-up started during the European Blue Green Dream (BGD) project (http: //bgd.org.uk/, last access: 22 April 2020, funded by ClimateKIC) that aimed to promote a change of paradigm for efficient planning and management of new or retrofitted urban developments by promoting the implementation of BGS (Maksimovic et al., 2013). Monitoring was anticipated and 
Table 1. Physical properties of the BGW substrate.

\begin{tabular}{lrrr}
\hline Initial composition of the substrate & Porosity & Dry density & $\begin{array}{r}\text { Saturated } \\
\text { hydraulic conductivity }\end{array}$ \\
\hline $\begin{array}{l}85 \% \text { of mineral matter and } \\
15 \% \text { of organic matter }\end{array}$ & $40 \%$ & $1442 \mathrm{~g} \mathrm{l}^{-1}$ & $8.11 \times 10^{-6} \mathrm{~m} \mathrm{~s}^{-1}$ \\
\hline
\end{tabular}

the building was adapted for experimental purposes during its construction. It was also supported by RadX@IdF, a regional project that aimed at analysing the benefits of highresolution rainfall measurement for urban storm-water management. Today the BGW is also part of the Fresnel multiscale observation and modelling platform created in the CoInnovation Lab at École des Ponts ParisTech. Fresnel aims to facilitate synergies between research and innovation, as well as the pursuit of theoretical research, the development of a network of international collaborations, and various aspects of data science (https://hmco.enpc.fr/portfolio-archive/ fresnel-platform/, last access: 22 April 2020).

From a technical point of view, the BGW is covered by two types of vegetation: green grass that represents the large majority of its area and a mix of perennial planting, grasses, and iris bulbs (see Fig. 1). Vegetation is laid out on a substrate layer of about $200 \mathrm{~mm}$ depth (SOPRAFLOR I966), a filter layer made of synthetic fibre (SOPRATEX 650), and a drainage layer made of expanded polystyrene (SOPRADRAIN). The vertical profile of the structure is presented in Fig. 2. The substrate was initially composed of volcanic soil (around $85 \%$ ) completed by organic matter. It is worth noting that $50 \%$ of the grains (in mass) are larger than $1.6 \mathrm{~mm}$ and $13 \%$ of fine particles are smaller than $80 \mu \mathrm{m}$. The main physical properties of the substrate are synthesized in Table 1 (see Stanic et al., 2019, for a detailed description including grain size distribution, water retention, and hydraulic conductivity curves).

From a hydrological point of view, the BGW is connected to three storage units that collect rainwater coming from the roof (with pipes) but also from several impervious parts around the greened building. One of the storage units is preceded by a smaller unit dedicated to irrigation. The water is then routed to a large retention basin to collect excess volumes of water during a rainfall event before being routed to the storm-water management network. This retention basin was designed (and oversized) because it was considered that the green roof (representing $50 \%$ of the total contributive area) was totally impervious without any retention capacity. Until now in France, there have been neither rules nor guidelines devoted to retention basin sizing that take into account the retention properties of green areas. Therefore the follow-up on such infrastructure is particularly important to develop new guidelines or legislations. For this purpose, the three components of the water balance have been monitored on the BGW. This experiment has been particularly focused on a significant drained area collecting only the green roof contribution $\left(3511 \mathrm{~m}^{2}\right)$. The implemented set-up is described in the following.

\subsection{Devices}

\subsubsection{Rainfall measurement}

Local rainfall has been analysed with the help of an optical disdrometer: Campbell Scientific ${ }^{\circledR}$ PWS100. This device is made of two receivers and a transmitter generating four laser sheets. By analysing the signals received from the light refracted by each drop passing through the $40 \mathrm{~cm}^{2}$ sampling area, the drop size and velocity are estimated. A rain rate can then be derived. Disdrometers are now considered to be a reliable rainfall measurement instrument (de Moraes Frasson et al., 2011; Gires et al., 2016; Thurai et al., 2011). The device has been installed since September 2013 on the roof of the École des Ponts ParisTech building (see Fig. 1). This disdrometer and its corresponding data have already been presented in detail in a previous data paper (Gires et al., 2018) that summarizes a measurement campaign that took place in January-February 2016. Here, the rainfall data provided by this disdrometer and characterized by a time step of $30 \mathrm{~s}$ have been used.

\subsubsection{Water content measurement}

Estimation of soil moisture represents a difficult challenge, as it deals with a highly spatially and temporally variable process (Lakshmi et al., 2003), essentially due to soil type and depth. Hence, suitable systems are required to properly assess soil moisture. Today a large number of sensors based on different methods are available for this purpose (Jackson et al., 2008). Among them, indirect methods based on electromagnetic (EM) principles have gained wide acceptance over the last decades. EM sensors have the advantage of delivering fast, in situ, non-destructive, and reliable measurements with acceptable precision (Stacheder et al., 2009).

Here the time domain reflectometry technique (TDR, also known as capacitance) has been selected. It is an EM moisture measurement that determines an electrical property called electrical conductivity or dielectric constant $\left(k_{a}\right)$. It is based on the interaction of an EM field with the soil water by using capacitance and frequency domain technology (Stacheder et al., 2009). The TDR sensor measures the propagation time of an EM pulse, generated by a pulse generator 
(a)

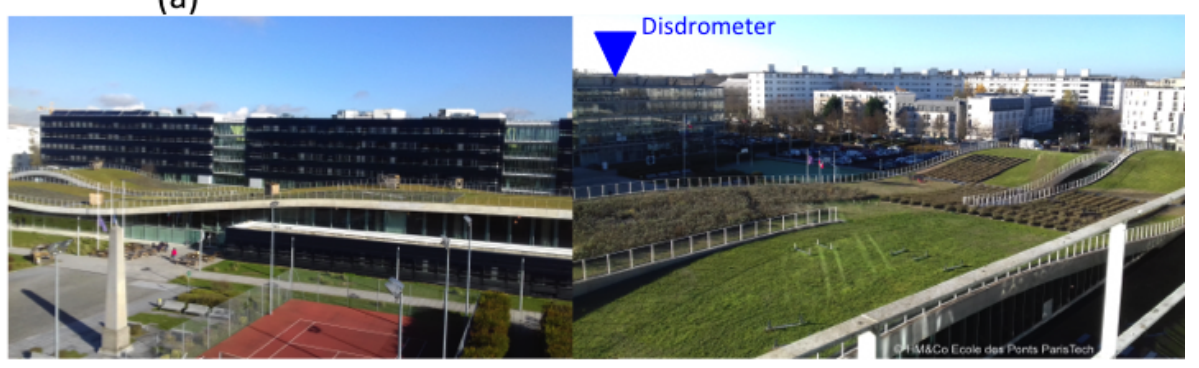

(b)

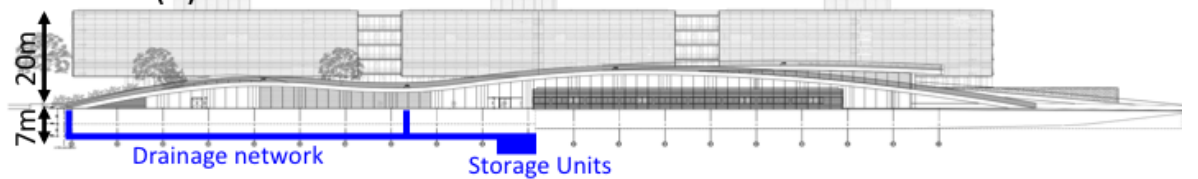

(c)

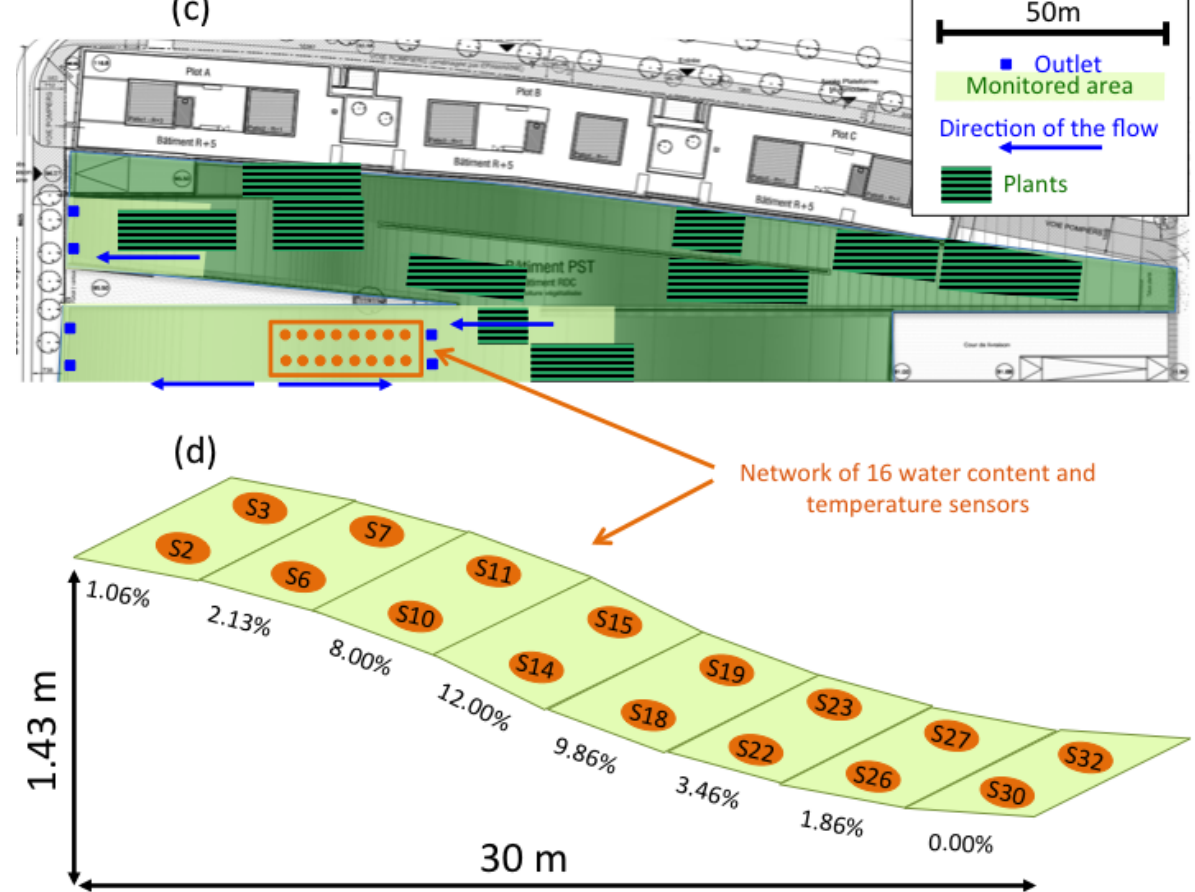

Figure 1. The Blue Green Wave monitoring site of ENPC: (a) pictures, (b) vertical representation and flow path lengths, (c) aerial representation showing the monitored area, and (d) profile of the section where the water content sensors were implemented indicating the slopes.

and containing a broad range of different measurement frequencies. The electrical pulse is applied to the waveguides (traditionally a pair of parallel metallic rods) inserted in the soil. The incident EM travels across the length of the waveguides and then is reflected back when it reaches the end of the waveguides. The travel time required for the pulse to reach the end of the waveguides and come back depends on the dielectric constant of the soil.

$k_{a}=\left(\frac{c \cdot \Delta t}{2 \cdot L}\right)$
Here $k_{a}$ is the bulk soil dielectric permittivity (unitless), $L$ the effective probe length $(\mathrm{m}), \Delta t$ the two-way travel time along the probe (s), and $c$ the velocity of EM wave in free space $\left(c=2.298 \times 10^{8} \mathrm{~m} \mathrm{~s}^{-1}\right)$

It is then possible to estimate soil moisture content by analysing the dielectric constant changes in the soil. The usual relationship between volumetric water content and dielectric constant is known as Topp's equation (Topp et al., 1980). It is adapted to a homogeneous conventional soil. Note that this substrate can be considered coarse enough to not clearly show the dielectric behaviour of a typical volcanic media (see Palla et al., 2009b, for a similar assumption). For 


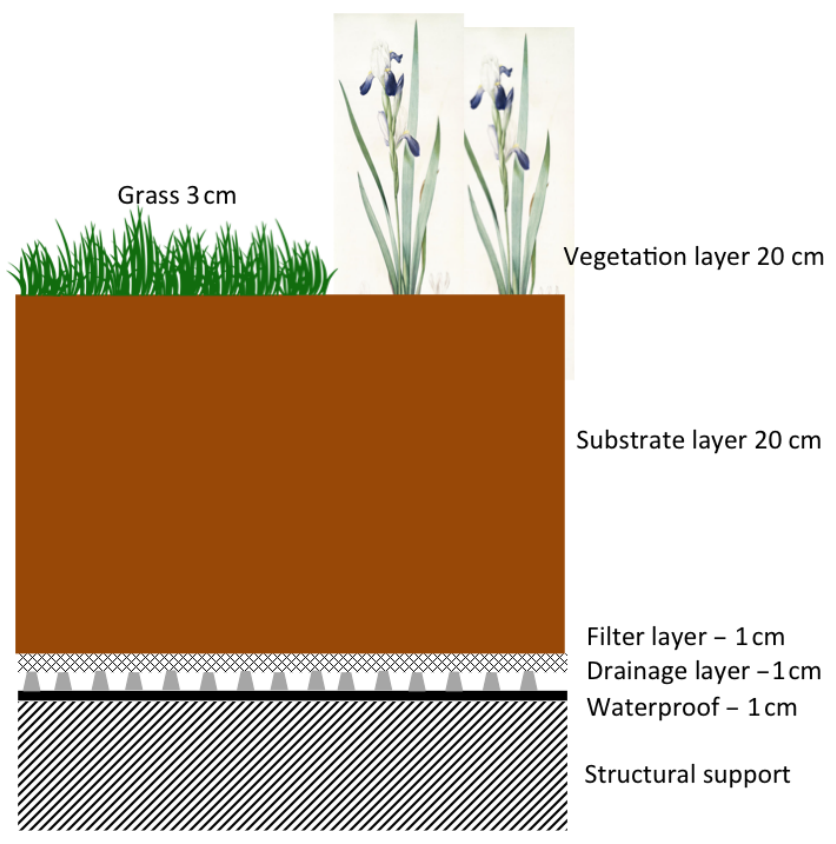

Figure 2. Vertical profile of the green wave structure.

this reason, it is assumed that the dielectric constant-water content relationship is not significantly different from the Topp equation:

$$
\begin{aligned}
\theta & =-5.3 \times 10^{-2}+2.92 \times 10^{-2} k_{a}-5.5 \times 10^{-4} k_{a}^{2} \\
& +4.3 \times 10^{-6} k_{a}^{3},
\end{aligned}
$$

where $\theta$ is the volumetric soil water content $\left(\mathrm{m}^{3} \mathrm{~m}^{-3}\right)$.

As an alternative to Topp's equation, an additional study was conducted to assess this relationship in lab. Here, for information, the calibration curve obtained with compaction better representing the current condition is displayed. This compaction was artificially mimicked by applying vibrations (this causes the segregation of the material similar to what occurs in situ during a long period of time).

$$
\begin{aligned}
\theta & =-3.01 \times 10^{-1}+1.13 \times 10^{-1} k_{a}-5.81 \times 10^{-3} k_{a}^{2} \\
& +9.85 \times 10^{-5} k_{a}^{3}
\end{aligned}
$$

Given that the dielectric data are provided, potential users are free to use Topp's equation as in this paper, or another equation.

Consequently, a ubiquitous wireless TDR sensor network has been implemented on the ENPC Blue Green Wave to measure both water content and temperature. For this purpose 32 CWS665 wireless TDR sensors (produced by Campbell Scientific ${ }^{\circledR}$ ) were initially installed. The data were collected by four CWB 100 wireless bases, able to each store the data of eight sensors. Then the data were transferred to a CR6 data logger from Campbell Scientific ${ }^{\circledR}$. The initial selected time step was $1 \mathrm{~min}$. It appeared that this first configuration was responsible for many gaps in the time series due to interference between the different TDR sensors and the bases. To avoid this problem, only 16 TDR sensors were used, all of them connected to the same CWB100 base. For this same reason of possible interferences between the sensors, the time interval was enlarged to $4 \mathrm{~min}$. Indeed, it is recommended to leave $15 \mathrm{~s}$ to ensure the connection of one sensor to the base. The final network aimed to capture the space-time variability of water content in a heterogeneous soil such as the BGW substrate. It was particularly adapted to assess the influence of the slope on infiltration and evapotranspiration processes.

\subsubsection{Discharge measurement}

Direct discharge measures are difficult to obtain in drainage pipes. For this reason, indirect measures using water level measurements are usually carried out. Here, water level inside the pipes was measured by a UM18 ultrasonic sensor (SICK, 2018) produced by SICK ${ }^{\circledR}$. This sensor has been especially developed to perform non-contact distance measurement or detection of objects. The sensor head emits an ultrasonic wave and receives the wave reflected back from the target. Ultrasonic sensors measure the distance to the target by measuring the time between the emission and reception. Implemented with the face to the water surface, it also measures the variation in the water level. The UM18 sensor is characterized by a nominal range of $250 \mathrm{~mm}$ and an accuracy of $1 \%$ for this measurement range. For the UM18 ultrasonic sensor, the dead zone is estimated to be $5 \mathrm{~mm}$. As the sensor has been placed on the top of the conduit, only very high values (higher than $240 \mathrm{~mm}$ ) could be affected by this dead zone. Since its implementation, water levels have never been higher than $120 \mathrm{~mm}$.

One UM18 sensor has been implemented inside a pipe located in the garage in the building basement (see Fig. 1). With a diameter of $300 \mathrm{~mm}$, this pipe collects the water coming from a large part of the BGW (approximately $1143 \mathrm{~m}^{2}$ ). A standard 4-20 mA current loop is used to monitor or remotely control these analogue sensors. The current is then transformed in voltage by a resistance of $100 \Omega$. The resulting transmitted signal ranges from 400 to $2000 \mathrm{mV}$. In order to translate the electric signal in water level values, the following relationship has been applied:

$H_{0}=(U-460) \times \frac{250}{1600}$.

$H_{0}$ is the water level in millimetres, $U$ the measured voltage in millivolts, 460 the offset, 250 the modified nominal range in millimetres, and 1600 the nominal range in millivolts.

The water level is then transformed into discharge by using the Manning-Strickler equation (Eq. 6). This formula is usually used to estimate the average velocity (and discharge) of water flowing in an open channel. It is commonly applied in sewer design containing circular pipes.

$Q_{0}=V \times S=K \times R^{\frac{2}{3}} \times i^{\frac{1}{2}} \times S$ 


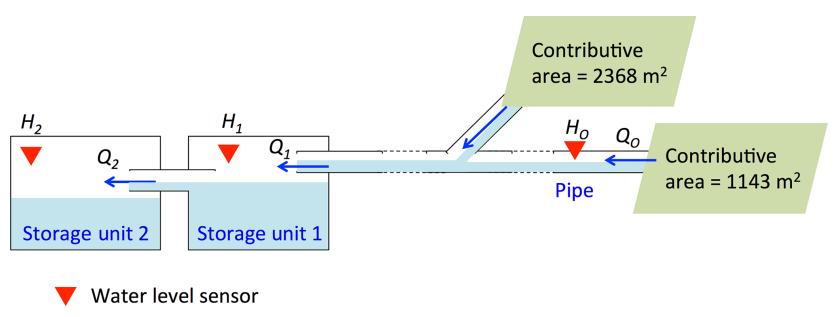

Figure 3. Location of the water level sensors in the storm-water management network.

Here $V$ is the average water velocity $\left(\mathrm{m} \mathrm{s}^{-1}\right), K$ the friction coefficient (unitless), $S$ the wet surface $\left(\mathrm{m}^{2}\right), R$ the hydraulic radius $(\mathrm{m})$, and $i$ the pipe slope $\left(\mathrm{m} \mathrm{m}^{-1}\right)$, which is equal to 0.0074 here. $R$ and $S$ are directly linked to the water level.

$R=\frac{S}{P}$

$S=\frac{(\theta-\sin (\theta)) \times r^{2}}{2}$

$P=r \times \theta$

$\theta=2 \times \arccos \left(\frac{r-H}{r}\right)$

$K$ has been chosen to be 85 . This value corresponds with a cast iron material.

Two additional UM18 sensors have been implemented in the two consecutive storage units (see Fig. 3) collecting the rainwater drained by a large contributive area of $3511 \mathrm{~m}^{2}$ and including the previous monitored area. The first storage unit is a rainwater tank (characterized by a floor area of $32.2 \mathrm{~m}^{2}$ ) devoted to irrigation. Filled most of the time, the excess water is routed by a pipe toward the second unit (floor area of $22.5 \mathrm{~m}^{2}$ ). A relationship similar to Eq. (5) between the voltage measurement and the water level has been adjusted for both units:

$H_{i}=(U-0.38) \times \frac{20}{1.62}-\mathrm{d} h$.

Here $U$ is the measured voltage in volts, the nominal range is $20 \mathrm{~cm}$, and $\mathrm{d} h$ (equal to $1.06 \mathrm{~cm}$ ) corresponds to an additional offset due to the elevation of the sensor

By studying both water level variations, a relationship between the water level measured in the first unit $\left(H_{1}\right)$ and the outflow routing to the second unit $Q_{2}$ (and related to $H_{2}$ ) has been established (see Fig. 4). Finally, the total discharge reaching the first unit and collecting the downstream rainfall can be assessed by the following equation depending only on $H_{1}$ :

$Q_{1}=Q_{2}+\frac{\mathrm{d} H_{1}}{\mathrm{~d} t} \times A 1=f\left(H_{1}\right)+\frac{\mathrm{d} H_{1}}{\mathrm{~d} t} \times A 1$,

where $Q_{1}$ is the discharge reaching the first unit and $Q_{2}$ the second unit; $A 1=33.2 \mathrm{~m}^{2}$ is floor area of the first unit.

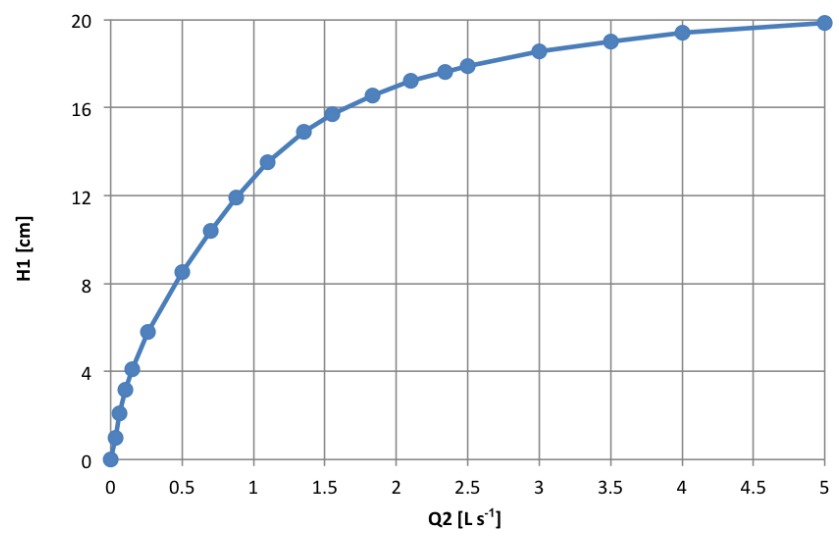

Figure 4. Relationship adjusted between the water level $H_{1}$ and the downstream discharge $Q_{2}$.

Finally, discharge data were recorded with a time step of $30 \mathrm{~s}$ for the sensor implemented in the conduit and $15 \mathrm{~s}$ for the one in the storage unit.

\subsection{Available output, data processing, and period of study}

As already presented in detail in Gires et al. (2018), precipitation data are collected in real time and stored through daily files. Here, these files for a $30 \mathrm{~s}$ time step rain rate have been gathered with the help of a Python script to create a long time series covering the whole period of study. Each line contains the time step expressed as YYYY-MM-DD HH:MM:SS and the corresponding rainfall intensity $\left(\mathrm{mm} \mathrm{h}^{-1}\right)$ separated by a comma.

Water content and water level data inside the pipe are collected and stored every night on the HM\&Co server in two different files. For this purpose, the Loggernet software produced by Campbell Scientific ${ }^{\circledR}$ has been used. It supports programming, communication, and data retrieval between data loggers and a PC. Concerning the water level file, each line corresponds to a time step for which the following information is recorded (in each line, these values are separated by a comma):

- exact definition of the time step expressed as YYYYMM-DD HH:MM:SS,

- item number,

- voltage indicator to ensure the quality of the measurement (it should be close to $12 \mathrm{~V}$ ),

- internal temperature of the data-logger box,

- unused data coming from a non-operational sensor,

- water level measured inside the pipe ( $U$ in Eq. 6, expressed in millivolts),

- unused data coming from a non-operational sensor, 
- unused data coming from a non-operational sensor.

A similar format has been chosen for volumetric water content data (note that names of the 16 volumetric water content (VWC) sensors are indicated in the header and are also reported in Fig. 1):

- exact definition of the time step expressed in YYYYMM-DD HH:MM:SS,

- item number,

- voltage indicator to ensure the quality of the measurement (it should be close to $12 \mathrm{~V}$ ),

- internal temperature of the data-logger box,

- volumetric water content (expressed as $k_{a}$ ) for the 16 TDR sensors,

- STT_B3: summary transfer time for basis, which is related to the total time required for collecting information from all the sensors that are collected to that base.

Water level data inside the storage units have been collected by using the open-source Arduino Uno microcontroller board that works in the offline regime. This Arduino system was chosen because the storage unit was instrumented a few months after the conduit and because the distance was too long to make a connection between the storage unit and the existing data logger. Data are continuously stored on the 64 MB memory card implemented in the board and copied manually to the HM\&Co server once per week. Data contain the following information (in each line, these values are separated by a space):

- item number,

- voltage values for the first storage unit - U1 (in millivolts),

- voltage values for the second storage unit - U2 (in millivolts),

- exact definition of the time step expressed in YYYYMM-DD HH:MM:SS.

By using Eq. (11) $U 1$ values are transformed into $H 1$ as a part of post-processing. Note that $U 2$ data have been used only for a short period of time after the implementation of UM18 sensors, until $Q 2=f(H 1)$ functionality has been obtained. After that they were no longer necessary.

\section{Data availability}

Contrary to rainfall and discharge, which are measured continuously at the same locations, water content sensors can be moved from one location to another on the BGW. Moreover, they were rarely kept installed during the night for security reason. Nevertheless, during several months at the beginning of 2018, they were maintained on the same section of the BGW (the one showed in Fig. 1). This time period corresponds to $78 \mathrm{~d}$, from 19 February to 7 May 2018. After this period, the water content sensors were moved to proceed to several evapotranspiration measurement campaigns on the BGW (see Conclusion section). This period has been selected to provide water balance components measurements to potential users. This data set is available for download from the following web page: https://doi.org/10.5281/zenodo.3687775 (Versini et al., 2019b).

\subsection{Presentation of the available data set}

This data set presented in detail in the next section contains the following files:

- a rainfall file, 2018_0219-0507_Data_rainfall.csv;

- a water content file, 2018_0219-0507_VWC.csv;

- a file of the water level inside the pipe, 2018_02190507_Data_discharge.csv;

- a file of the water level in the storage, 2018_02190507_Data_Arduino.csv;

- a Python script to select the data, transform the raw data in physical measurements, and carry out some initial analysis.

In detail, the Python script is structured as follows.

- Time period selection. This part could be changed to select a study time period by choosing an initial and final date.

- Data selection and transformation. The data corresponding to this time period are selected in the different files. Electric signals measured by the water level sensors are converted in water level (by using Eqs. 5 and 11) and then in discharge by using the ManningStrickler equation (Eq. 6) for the pipe and Eq. (12) for the storage unit. In order to smooth the erratic $15 \mathrm{~s}$ signal produced by storage unit measurements, the computed discharge data are averaged on a moving window, whose number of time steps can be modified. Dielectric constants measured by the 16 TDR sensors are converted in water content by using the Topp equation (Eq. 3).

- Representation of the computed data. Several figures are plotted to illustrate the variation in the hydrological components in time. The first one represents the corresponding hydrographs for both discharges computed inside the pipe and in the storage unit. The second one synthesizes the water content measured by the 16 TDR 
sensors. In each figure, the precipitation is drawn on an inverted $y$ axis.

- Computation of runoff coefficients. Runoff coefficient is the ratio between the total amount of precipitation (computed by multiplying the rain depth by the corresponding contributive area) and the total volume of water flowing through the monitored pipe or the storage unit. This value ranging from $0 \%$ to $100 \%$ illustrates the capacity of the green roof to retain rainwater.

\subsection{Presentation of the time series}

During the available time period including half of winter and half of spring, it rained a total amount of $123.1 \mathrm{~mm}$ (see Fig. 5). The rainfall file has no missing value, and six rainfall events can be defined. They correspond to periods with cumulative rainfall depths greater than $5 \mathrm{~mm}$ (separated by a dry period of at least $6 \mathrm{~h}$ ) that caused discharge in both the pipe and storage unit: 7 March $(9 \mathrm{~mm}), 11$ March $(9.7 \mathrm{~mm})$, 17 March $(7.5 \mathrm{~mm}), 27$ and 28 March $(13.9 \mathrm{~mm}), 9$ April $(9.6 \mathrm{~mm})$, and 29 and 30 April $(23.5 \mathrm{~mm})$. These events are obviously not representative of the full range of precipitation events in the area. Nevertheless, it has to be mentioned that since the BGW was monitored (2017), intense rainfall has never caused any flooding on the surface or pipe filling (the higher water level measured was about $12 \mathrm{~cm}$ ).

Concerning the 16 VWC sensors, $5.6 \%$ of the time steps are considered to be missing data. This is essentially due to two particular sensors that were out of service from 16 March to the end of the study time period. The 16 sensors follow the same dynamic, responding to the several rainfall events (see Fig. 6). Water content measurements decrease simultaneously during two long dry periods, at the end of February and from mid-April to the beginning of May. The sensors show a significant spatial variability in terms of absolute values. These differences illustrate the heterogeneousness of the substrate profiles in terms of hydrological behaviour. This is due to the granular composition of the substrate but also to the wavy form of the BGW. Indeed, the lowest values tend to refer to the upstream sensors, whereas the highest values tend to refer to the downstream ones. Note that the grain size distribution time evolution is difficult to assess. Only the loss of some small particles has been noticed in the conduits.

Discharge data are almost complete. Only one measurement is missing in the pipe and $0.2 \%$ of the total number of time steps for the storage unit. These missing data correspond to the short periods during which the manual collection of the data was carried out. Note that in order to avoid the loss of relevant data, this collection was done during a dry period. Over this time period of $78 \mathrm{~d}$, the runoff coefficient computed for both pipe and storage unit is equal to $70.6 \%$ and $71.1 \%$ respectively. These close values demonstrate the suitability of the monitored set-up. The missing water corresponds to the water retained by the substrate and the

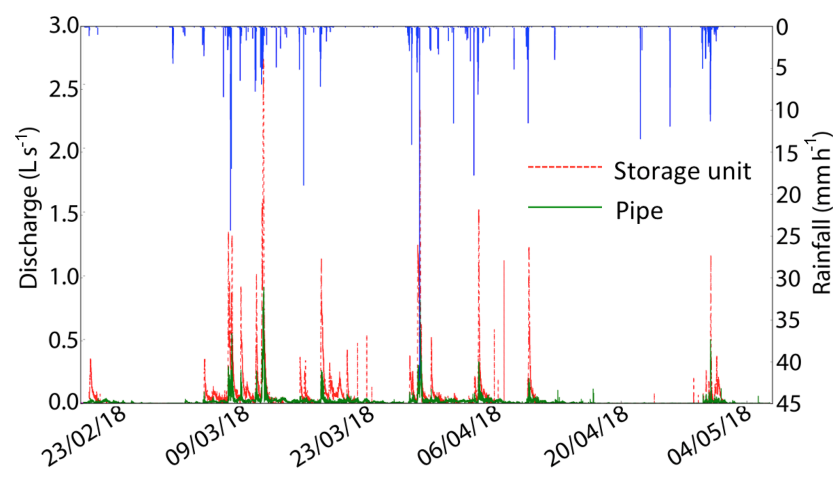

Figure 5. Rainfall and computed discharges for the whole time period.

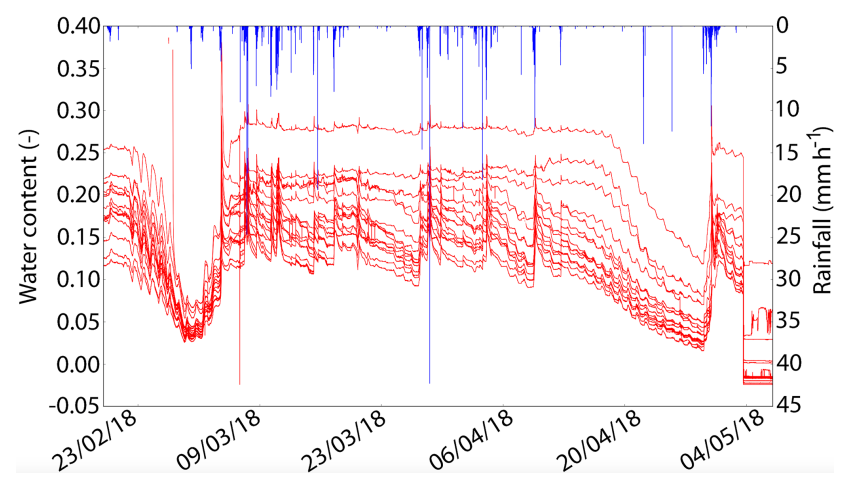

Figure 6. Rainfall and volumetric water content $\left(\mathrm{m}^{3} \mathrm{~m}^{-3}\right)$ for 16 TDR sensors.

vegetation. It should be returned to the atmosphere by evapotranspiration. As already mentioned, Topp's equation (Eq. 3) used to convert the dielectric constant to water content could not be adapted to the specific substrate used for the BGW. For this reason, the dielectric constant data are provided, leaving the reader free to use another relationship to convert these data into water content.

\subsection{Illustration with a particular event}

The 29 and 30 April rainfall event is presented in details in this section. It corresponds to the most intense event with a total cumulative rainfall depth of $23.5 \mathrm{~mm}$. Figure 7 shows the corresponding hydrograph from which the delay between rainfall and discharge peaks can be deduced. It reaches $1 \mathrm{~h}$ for the first contributive area (drained to the pipe) and $1.5 \mathrm{~h}$ for the second one (drained to the storage unit).

Regarding the question of coherency with previous studies (Palla et al., 2009b, for instance), the water content difference was computed with Topp's equation. The water stored in the substrate during this event was assessed according to the difference between initial and final values. For the 16 sensors, this value ranges between $9.8 \%$ and $13.7 \%$. This corresponds to a water depth of between 19.6 and $27.2 \mathrm{~mm}$ and a 


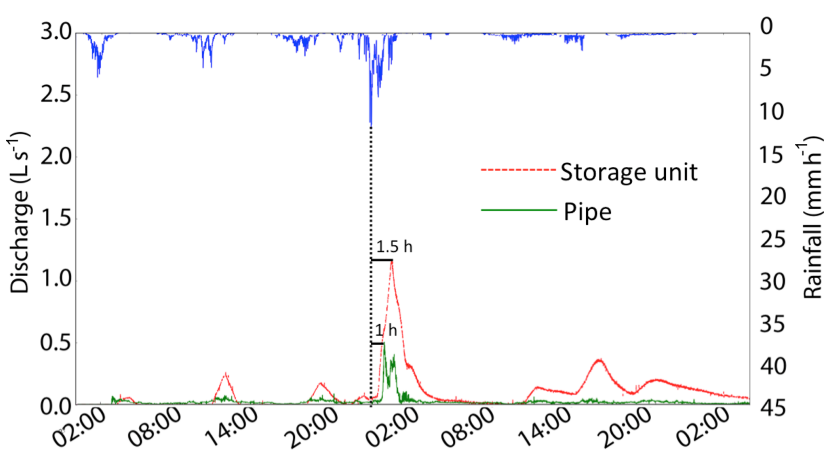

Figure 7. Rainfall and computed discharges for the 2930 April 2018 event.

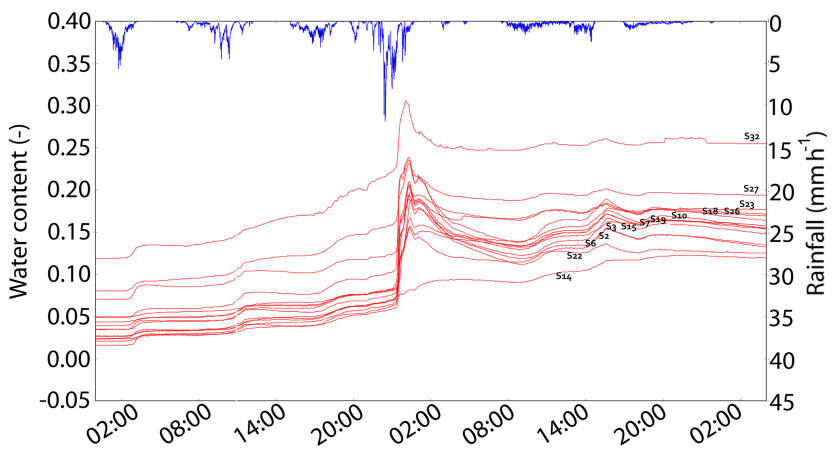

Figure 8. Rainfall and volumetric water content $\left(\mathrm{m}^{3} \mathrm{~m}^{-3}\right)$ for 16 TDR sensors for the 29-30 April 2018 event (sensor references are indicated by an increasing value at the end of the event).

storage capacity between $83 \%$ and higher than $100 \%$ of the rainfall (note that a range of between 20.6 and $30.0 \mathrm{~mm}$ is obtained with the lab relationship presented in Eq. 4). It is clear the larger values are overestimated but the order of magnitude is consistent with the computed runoff coefficients: $15 \%$ for the surface drained to the pipe and $22 \%$ for the surface drained to the storage unit. This result illustrates the retention and detention properties of the green roof. It has to be recalled that these impacts differ from one event to another depending on the precipitation and the initial conditions.

\section{Conclusions}

This paper presents the data collected by several devices devoted to the assessment of the water balance of a particular green roof located close to Paris. The data set made available for research purposes contains three types of data, representing the relevant components of the water balance during a rainfall event: rainfall, water content in the substrate, and the discharge flowing out of the infrastructure. These data were collected during $78 \mathrm{~d}$ between February and May 2018. These measurements are useful to study the capacity of such vegetated structures to store rainwater and act as a stormwater management tool. They could also be useful to develop and validate some appropriate modelling approaches (Stovin et al., 2013; Versini et al., 2016).

This data set is available for download free of charge from the following web page: https://doi.org/10.5281/zenodo.3687775 (Versini et al., 2019b).

It is provided by the Hydrology, Meteorology, and Complexity laboratory of École des Ponts ParisTech (HM\&CoENPC). The following references should be cited for every use of the data: Versini et al. (2019a, this paper).

Research focused on the assessment of ecosystem services provided by Blue Green Solutions is continuing at HM\&CoENPC, and particularly on the BGW. The monitoring set-up has been recently extended to the energy balance component measurement (radiation balance, conduction, sensitive and latent heat flux) and particularly to the evapotranspiration flux. Such data will be particularly useful to study the ability of Blue Green Solutions to mitigate urban heat islands (but also to assess their retention potential during dry periods). The French ANR EVNATURB project (https://hmco.enpc.fr/ portfolio-archive/evnaturb/, last access: 22 April 2020) that aims to develop a platform to assess some of the ecosystem services (i.e. storm-water management, cooling effect, or biodiversity conservation) provided by BGS is now pursuing this work of monitoring (Versini et al., 2017).

Author contributions. P-AV supervised the study and reviewed and wrote a large part of the manuscript; FS and AG worked on the implementation of some of the presented sensors and the collection of the data and participated in the review of the paper; DS and IT collaborated on the study supervision and the review process.

Competing interests. The authors declare that they have no conflict of interest.

Acknowledgements. This work was initiated during the ClimateKIC-funded Blue Green Dream project (http://bgd.org.uk/, last access: 22 April 2020). It has also been supported by the Academic Chair "Hydrology for Resilient Cities", a partnership between École des Ponts ParisTech and the Veolia group, and the ANR EVNATURB project dealing with the evaluation of ecosystem performance for renaturing urban environments.

Financial support. This research has been supported by the Climate-KIC, the Academic Chair "Hydrology for Resilient Cities", and the French Agence Nationale de la Recherche (ANR-17-CE220002-01).

Review statement. This paper was edited by David Carlson and reviewed by two anonymous referees. 


\section{References}

Berndtsson, J. C.: Green roof performance towards management of runoff water quantity and quality: A review, Ecol. Eng., 36, 351360, https://doi.org/10.1016/j.ecoleng.2009.12.014, 2010.

Berretta, C., Poë, S., and Stovin, V.: Moisture content behaviour in extensive green roofs during dry periods: The influence of vegetation and substrate characteristics, J. Hydrol., 511, 374-386, https://doi.org/10.1016/j.jhydrol.2014.01.036, 2014.

Buffam, I., Mitchell, M. E., and Durtsche, R. D.: Environmental drivers of seasonal variation in green roof runoff water quality, Ecol. Eng., 91, 506-514, https://doi.org/10.1016/j.ecoleng.2016.02.044, 2016.

Cipolla, S. S., Maglionico, M., and Stojkov, I.: A longterm hydrological modelling of an extensive green roof by means of SWMM, Ecol. Eng., 95, 876-887, https://doi.org/10.1016/j.ecoleng.2016.07.009, 2016.

Fassman-Beck, E., Voyde, E., Simcock, R., and Hong, Y. S.: 4 Living roofs in 3 locations: Does configuration affect runoff mitigation?, J. Hydrol., 490, 11-20, https://doi.org/10.1016/j.jhydrol.2013.03.004, 2013.

Feng, Y., Burian, S., and Pardyjak, E.: Observation and Estimation of Evapotranspiration from an Irrigated Green Roof in a Rain-Scarce Environment, Water, 10, 262, https://doi.org/10.3390/w10030262, 2018.

Francis, L. F. M. and Jensen, M. B.: Benefits of green roofs: A systematic review of the evidence for three ecosystem services, Urban For. Urban Green, 28, 167-176, https://doi.org/10.1016/j.ufug.2017.10.015, 2017.

de Moraes Frasson, R. P., da Cunha, L. K., and Krajewski, W. F.: Assessment of the Thies optical disdrometer performance, Atmos. Res., 101, 237-255, https://doi.org/10.1016/j.atmosres.2011.02.014, 2011.

Getter, K. L., Rowe, D. B., and Andresen, J. A.: Quantifying the effect of slope on extensive green roof stormwater retention, Ecol. Eng. 31, 225-231, https://doi.org/10.1016/j.ecoleng.2007.06.004, 2007.

Gires, A., Tchiguirinskaia, I., and Schertzer, D.: Two months of disdrometer data in the Paris area, Earth Syst. Sci. Data, 10, 941950, https://doi.org/10.5194/essd-10-941-2018, 2018.

Gires, A., Tchiguirinskaia, I., and Schertzer, D.: Multifractal comparison of the outputs of two optical disdrometers, Hydrol. Sci. J., 61, 1641-1651, https://doi.org/10.1080/02626667.2015.1055270, 2016.

Hakimdavar, R., Culligan, P. J., Guido, A., and McGillis, W. R.: The Soil Water Apportioning Method (SWAM): An approach for long-term, low-cost monitoring of green roof hydrologic performance, Ecol. Eng., 93, 207-220, https://doi.org/10.1016/j.ecoleng.2016.05.023, 2016.

Jackson, T., Mansfield, K., Saafi, M., Colman, T., and Romine, P.: Measuring soil temperature and moisture using wireless MEMS sensors, Measurement, 41, 381-390, https://doi.org/10.1016/j.measurement.2007.02.009, 2008.

Johannessen, B., Muthanna, T., and Braskerud, B.: Detention and Retention Behavior of Four Extensive Green Roofs in Three Nordic Climate Zones, Water, 10, 671, https://doi.org/10.3390/w10060671, 2018.

Lakshmi, V., Jackson, T. J., and Zehrfuhs, D.: Soil moisture-temperature relationships: results from two field experiments, Hydrol. Process., 17, 3041-3057, https://doi.org/10.1002/hyp.1275, 2003.

Li, Y. and Babcock, R. W.: Modeling Hydrologic Performance of a Green Roof System with HYDRUS-2D, J. Environ. Eng., 141, 4015036, https://doi.org/10.1061/(ASCE)EE.19437870.0000976, 2015.

Locatelli, L., Mark, O., Mikkelsen, P. S., Arnbjerg-Nielsen, K., Bergen Jensen, M., and Binning, P. J.: Modelling of green roof hydrological performance for urban drainage applications, J. Hydrol., 519, 3237-3248, https://doi.org/10.1016/j.jhydrol.2014.10.030, 2014.

Loiola, C., Mary, W., and Pimentel da Silva, L.: Hydrological performance of modular-tray green roof systems for increasing the resilience of mega-cities to climate change, J. Hydrol., 573, 1057-1066, https://doi.org/10.1016/j.jhydrol.2018.01.004, 2019.

Maksimovic, C., Stankovic, S., Liu, X., and Lalic, M.: Blue green dream project's solution for urban areas in the future, International science conference reporting for sustainability, Becici, Montenegro, 7-10 May 2013, 49-54, 2013.

Oberndorfer, E., Lundholm, J., Bass, B., Coffman, R. R., Doshi, H., Dunnett, N., Gaffin, S., Köhler, M., Liu, K. K. Y., and Rowe, B.: Green Roofs as Urban Ecosystems: Ecological Structures, Functions, and Services, BioScience, 57, 823-833, https://doi.org/10.1641/B571005, 2007.

Ouldboukhitine, S.-E., Belarbi, R., Jaffal, I., and Trabelsi, A.: Assessment of green roof thermal behavior: A coupled heat and mass transfer model, Build. Environ, 46, 2624-2631, https://doi.org/10.1016/j.buildenv.2011.06.021, 2011.

Palla, A., Gnecco, I., and Lanza, L. G.: Unsaturated 2D modelling of subsurface water flow in the coarse-grained porous matrix of a green roof, J. Hydrol., 379, 193-204, https://doi.org/10.1016/j.jhydrol.2009.10.008, 2009a.

Palla, A., Gnecco, I., and Lanza, L. G.: Unsaturated 2D modelling of subsurface water flow in the coarse-grained porous matrix of a green roof, J. Hydrol., 379, 193-204, https://doi.org/10.1016/j.jhydrol.2009.10.008, 2009b.

Petrucci, G., Rioust, E., Deroubaix, J.-F., and Tassin, B.: Do stormwater source control policies deliver the right hydrologic outcomes?, J. Hydrol., 485, 188-200, https://doi.org/10.1016/j.jhydrol.2012.06.018, 2013.

Poë, S., Stovin, V., and Berretta, C.: Parameters influencing the regeneration of a green roof's retention capacity via evapotranspiration, J. Hydrol., 523, 356-367, https://doi.org/10.1016/j.jhydrol.2015.02.002, 2015.

SICK: OPERATING INSTRUCTIONSUM18-2 ProUltrasonic sensors, tecnical manual, 2018.

Stacheder, M., Koeniger, F., and Schuhmann, R.: New Dielectric Sensors and Sensing Techniques for Soil and Snow Moisture Measurements, Sensors, 9, 2951-2967, https://doi.org/10.3390/s90402951, 2009.

Stanic, F., Cui, Y. J., Versini, P.-A., Schertzer, D., and Tchiguirinskaia, I.: A device for the simultaneous determination of the water retention properties and the hydraulic conductivity of an unsaturated green-roof material, Geotech. Test. J., 43, 20170443, https://doi.org/10.1520/GTJ20170443, 2019.

Stovin, V., Vesuviano, G., and Kasmin, H.: The hydrological performance of a green roof test bed under UK climatic conditions, J. Hydrol., 414-415, 148-161, https://doi.org/10.1016/j.jhydrol.2011.10.022, 2012. 
Stovin, V., Poë, S., and Berretta, C.: A modelling study of long term green roof retention performance, J. Environ. Manage., 131, 206-215, https://doi.org/10.1016/j.jenvman.2013.09.026, 2013.

Stovin, V., Poë, S., De-Ville, S., and Berretta, C.: The influence of substrate and vegetation configuration on green roof hydrological performance, Ecol. Eng., 85, 159-172, https://doi.org/10.1016/j.ecoleng.2015.09.076, 2015.

Thurai, M., Petersen, W. A., Tokay, A., Schultz, C., and Gatlin, P.: Drop size distribution comparisons between Parsivel and 2-D video disdrometers, Adv. Geosci., 30, 3-9, https://doi.org/10.5194/adgeo-30-3-2011, 2011.

Topp, G. C., Davis, J. L., and Annan, A. P.: Electromagnetic determination of soil water content: Measurements in coaxial transmission lines, Water Resour. Res., 16, 574-582, https://doi.org/10.1029/WR016i003p00574, 1980.

Versini, P.-A., Gires, A., Tchinguirinskaia, I., and Schertzer, D.: Toward an operational tool to simulate green roof hydrological impact at the basin scale: a new version of the distributed rainfallrunoff model Multi-Hydro, Water Sci. Technol., 74, 1845-1854, https://doi.org/10.2166/wst.2016.310, 2016.

Versini, P.-A., Tchiguirinskaia, I., and Schertzer, D.: The EVNATURB project: toward an operational platform to assess Blue Green Solutions eco-systemic services in urban environment, AGU Conference, New Orleans, USA, 2017.
Versini, P.-A., Gires, A., Fitton, G., Tchiguirinskaia, I., and Schertzer, D.: Toward an assessment of the hydrological components variability in green infrastructures: Pilot site of the Green Wave (Champs-sur-Marne), Houille Blanche, 4, 34-42, https://doi.org/10.1051/lhb/2018040, 2018.

Versini, P.-A., Stanic, F., Gires, A., Schertzer, D., and Tchinguirinskaia, I.: Data for "Measurement of the water balance components of a large green roof in Greater Paris Area", Zenodo, https://doi.org/10.5281/zenodo.3467300, 2019a.

Versini, P.-A., Stanic, F., Gires, A., Schertzer, D., and Tchinguirinskaia, I.: Blue Green Wave hydrological data, Zenodo, https://doi.org/10.5281/zenodo.3687775, 2019b.

Wong, G. K. L. and Jim, C. Y.: Identifying keystone meteorological factors of green-roof stormwater retention to inform design and planning, Landsc. Urban Plan., 143, 173-182 https://doi.org/10.1016/j.landurbplan.2015.07.001, 2015.

Zhang, Q., Miao, L., Wang, X., Liu, D., Zhu, L., Zhou, B., Sun, J., and Liu, J.: The capacity of greening roof to reduce stormwater runoff and pollution, Landsc. Urban Plan., 144, 142-150, https://doi.org/10.1016/j.landurbplan.2015.08.017, 2015. 